\title{
Umbilical Hernia in Children at the Pediatric Surgery Unit of Fousseyni Daou Hospital in Kayes
}

\author{
Kouyate $\mathrm{M}^{1,2^{*}}$, Sangare $\mathrm{S}^{2,3}$, Sogoba $\mathrm{G}^{2,3}$, Dicko $\mathrm{B}^{4}$, Diakite $\mathrm{A}^{2,5}$, Magassa $\mathrm{M}^{2,5}$, Kane $\mathrm{M}^{6}$, Dembele $\mathrm{T}^{7}$
}

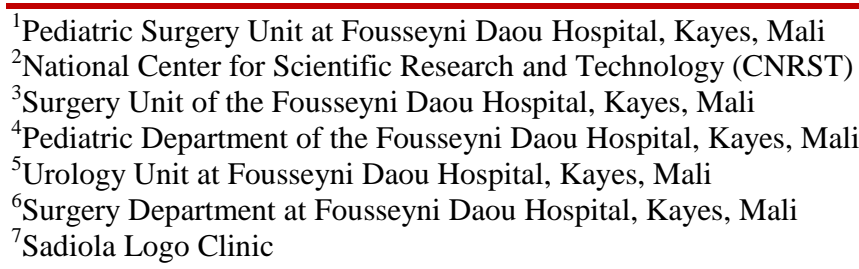

DOI: $10.36347 /$ sasjs.2022.v08i01.004

| Received: 02.12.2021 | Accepted: 06.01.2022 | Published: 12.01.2022

*Corresponding author: Kouyate $\mathrm{M}$

Pediatric Surgery Unit at Fousseyni Daou Hospital, Kayes, Mali

Abstract Original Research Article

Introduction: A disease characterized by the protrusion of part of the intestine through the abdominal muscles at the level of the navel. Many infants are born with umbilical hernia especially in Africa. Materials and Methods: We conducted a retrospective study from January 2018 to December 2020. The objectives were to determine the hospital frequency of umbilical hernia at the regional hospital of Kayes, to describe the clinical and para-clinical aspects and finally to describe the immediate aftermath of surgical treatment. Results: During the period Janvier 2018 Décembre 2020, we consulted 1108 pediatric surgery patients and performed 805 surgical procedures including 76 umbilical hernias. The umbilical hernia has re present $9.5 \%$ of all surgical procedures, $25 \%$ of hernias in children $8.3 \%$ of hospitalizations and a hospital frequency of $6.8 \%$. The age group of 3 to 6 years was the most represented with $40.3 \%$, the male sex was the most represented with 59\%. Conclusion: Umbilical hernia is a frequent pathology, especially in Africa, whose diagnosis is clinical.

Keywords: Umbilical hernia, hospital, Kayes.

Copyright $(\mathcal{C} 2022$ The Author(s): This is an open-access article distributed under the terms of the Creative Commons Attribution 4.0 International License (CC BY-NC 4.0) which permits unrestricted use, distribution, and reproduction in any medium for non-commercial use provided the original author and source are credited.

\section{INTRODUCTION}

The umbilical hernia is the consequence of a delay or an abnormality in the closure of the umbilical musculo-aponeurotic orifice. It presents as a more or less voluminous swelling (of one or several centimeters).

It is a benign pathology which spontaneously progresses most often to complete regression in the first 4 years of life.

In the United States of America, Garcia in 2000 found in a comparative study an increased umbilical frequency in black children $12 \%$ [6].

\section{MATERIALS AND METHODS}

We conducted a retrospective from January 2018 to December 2020. The objectives were to determine the hospital frequency of umbilical hernia at the Kayes regional hospital, describe the clinical and para-clinical aspects and finally describe the immediate postoperative consequences of surgical treatment.

The other types of hernias were excluded. It was carried out on the software WORD, SPSS 10.0, Epi info version 6.0 Fr.

\section{RESULTS}

During the study period, we performed 805 surgeries; the age group of 3 to 6 years was the most represented with $40.8 \%$. The minimum age was 6 months, the maximum age 12 . The predominant sex was male. Most of our patients resided in Kayes and there was a Senegalese and a Mauritanian presence. The majority of our patients did not have a medical history, ie $60.5 \%$. The swelling was painful and reducible in $55.3 \%$ of cases, but painful and irreducible in $39.5 \%$ 
therefore strangled. Among the strangulated hernias only one underwent resection with end-to-side anastomosis, as a result of ileocecal necrosis.
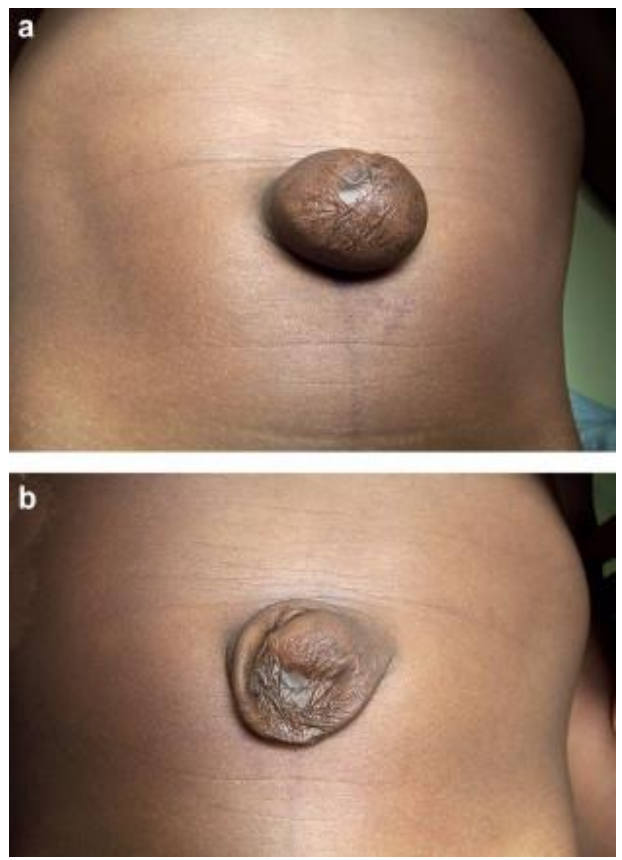

Ombical Hernia

\section{COMMENTS AND DISCUSSIONS}

This was a prospective study from January 2018 to December 2020. We followed up the patients and we encountered problems such as the difficulty of postoperative follow-up due to non-compliance with appointments.

The umbilical hernia is a pathology especially frequent in Africa [4, 2]. The frequency of umbilical hernia varies between $5 \%$ and $12 \%$ [4], our result is $6.8 \%$ which does not differ statistically from that of African authors $[1,7]$.

Preterm birth or low birth weight are contributing factors to umbilical hernia [7,8]. In our series 2 cases of premature babies were observed.
Male sex appears to be a risk factor for umbilical hernia [5]. We recorded a ratio of 1.4 in favor of the male sex.

Preterm birth or low birth weight are contributing factors to umbilical hernia [7, 8]. In our series 2 cases of premature babies were observed.

Male sex appears to be a risk factor for umbilical hernia [5]. We recorded a ratio of 1.4 in favor of the male sex.

The umbilical hernia is a pathology poor in functional sign; pain is usually found in complications. This abdominal pain was the main functional sign with a frequency of $95 \%$ (cf: Table I). This rate does not differ statistically from that of Brown in England [3] and 'Ameh in Nigeria [1]. Collar found in the English and Nigerian series could explain the occurrence of the pain.

Other signs have been found in addition to pain in the literature [3], such as vomiting, material and gas. Knowing the neck is extremely important in the management of umbilical hernia [6], it is the main risk factor for strangulation [4]. In our study, the mean diameter of $3.7 \mathrm{~cm}$ does not differ from the Nigerian [4] and Senegalese [8] series (cf: Table III).

According to the literature, recurrent hernia infatuation is serious and can progress to visceral injury; it most often precedes the strangulation [3, 4]. In our study, this rate of $34.2 \%$ infatuation did not differ from those of fall in Senegal [8] and keshgar in London with $\mathrm{p}$ greater than 0.05 . When the strangulation lasts more than 6 hours in surgery digestive tract the risk of intestinal necrosis is great. Only one of our patients was received within 4 days of the strangulation and underwent end-to-lateral ileocecal anastomosis resection.

In our study, the overcoat technique and that of the single point closure were the techniques most used in surgery with $86.8 \%$ and $13 \%$ respectively (see Table $\mathrm{V})$.

Table I: Distribution of patients according to functional signs
\begin{tabular}{|l|l|l|}
\hline Signes fonctionnels & Effectifs & Percentage \\
\hline Abdominal pain & $72 / 76$ & $94,7 \%$ \\
\hline Vomiting & $32 / 76$ & $42,1 \%$ \\
\hline Stopping of materials and gases & $18 / 76$ & $23,7 \%$ \\
\hline
\end{tabular}

Abdominal pain was the main functional sign, $94.7 \%$

Table II: Distribution of patients according to the nature of the swelling on palpation

\begin{tabular}{|l|l|l|}
\hline Character of swelling on palpation & Effective & Percentage \\
\hline Reducible painful swelling & 42 & $55,3 \%$ \\
\hline Irreducible painful swelling & 30 & $39,5 \%$ \\
\hline Painless swelling & 4 & $5,2 \%$ \\
\hline Total & 76 & $100 \%$ \\
\hline
\end{tabular}

Reducible painful swelling was the most represented, ie $55.3 \%$. 
Table III: Distribution of patients by neck diameter

\begin{tabular}{|l|l|l|}
\hline Character of swelling on palpation & Effectif & Pourcentage \\
\hline Between 0.5 to $1.5 \mathrm{~cm}$ & $\mathbf{4 3}$ & $\mathbf{5 6 , 5 \%}$ \\
\hline Greater than $1.5 \mathrm{~cm}$ & 33 & $43,4 \%$ \\
\hline Total & 76 & $100 \%$ \\
\hline
\end{tabular}

The mean diameter of the collar was $2.41 \mathrm{~cm}$ with extremes of 0.5 and $4.5 \mathrm{~cm}$

Table IV: Distribution of patients according to the content of the strangulated hernia sac

\begin{tabular}{|l|l|l|}
\hline Contents of the bag & Effectif & Pourcentage \\
\hline Small intestine & $\mathbf{2 3}$ & $\mathbf{7 6 , 7 \%}$ \\
\hline Omentum & 6 & $20 \%$ \\
\hline Colon plus Small Intestine & 1 & $3,3 \%$ \\
\hline Total & 30 & $100 \%$ \\
\hline
\end{tabular}

The contents were from the small intestine in $76.7 \%$ of strangulated hernia cases.

Table V: Repair of hernias according to the technique used

\begin{tabular}{|l|l|l|}
\hline Surgical technique used & Effectif & Pourcentage \\
\hline Closure in overcoat (Mayo) & $\mathbf{6 6}$ & $\mathbf{8 6 , 8 \%}$ \\
\hline Single point closure & 10 & $13,2 \%$ \\
\hline Total & 76 & $100 \%$ \\
\hline
\end{tabular}

Closure in overcoat was performed in 66 patients, or $86.8 \%$

\section{CONCLUSION}

Umbilical hernia is a common pathology in Africa in children, the main complication is strangulation; the diagnosis is mainly clinical and the management is surgical.

\section{REFERENCES}

1. Ameh, E. A., Chirdan, L. B., Nmadu, P. T., \& Yusufu, L. M. (2003). Complicated umbilical hernias in children. Pediatric surgery international, 19(4), 280-282.

2. Bouchet, A., \& Cuilleret, J. (1989). Anatomie topographique descriptive et fonctionnelle. Tome 4, $2^{\text {eme }}$ édition Simep Paris 5.

3. Brown, R. A., Numanoglu, A., \& Rode, H. (2006). Hernie ombilicale compliquées dans l'enfance. $S$ Afr J Surg, 44(4), 136-137.

4. Chirdan, L. B., Uba, A. F., \& Kidmas, A. T. (2006). Incarcerated umbilical hernia in children. European journal of pediatric surgery, 16(01), 45-48.

5. Fall, I., Sanou, A., Ngom, G., Dieng, M., Sankalé, A. A., \& Ndoye, M. (2006). Strangulated umbilical hernias in children. Pediatric surgery international, 22(3), 233-235.

6. Feins, N. R., Dzakovic, A., \& Papadakis, K. (2008). Minimally invasive closure of pediatric umbilical hernias. Journal of pediatric surgery, 43(1), 127-130.

7. Garcia, V. F. (2000). Umbilical hernia and other abdominal wall hernia Pediatric surgery Saunders, philadelphia, pp. 651-653.

8. Sankale, A. A., Ngom, G., Fall, I., Coulibaly, N. F., \& Ndoye, M. (2004, February). Umbilical reconstruction in children. Prospective report of 77 cases. In Annales de chirurgie plastique et esthetique, 49(1), pp. 17-23. 